\title{
Grain Growth in Sintered Natural Hydroxyapatite
}

\author{
E. Harabi*, A. Harabi, L. Foughali, S. Chehlatt, S. Zouai, F.Z. Mezahi \\ Faculty of Exact Science, Physics department, Ceramics Lab., Constantine University 1, Constantine 25000, Algeria.
}

\begin{abstract}
Hydroxyapatite (HA: $\left.\mathrm{Ca}_{10}\left(\mathrm{PO}_{4}\right)_{6}(\mathrm{OH})_{2}\right)$ can be synthesized using several methods or manufactured from natural materials such as coral or bone after removal of the organic matter by heating (denoted as NHA). The "in vitro" and "in vivo" studies showed that the natural apatite was well tolerated and has better osteoconductive properties than synthetic HA. In addition, the exploitation of natural source represents an economical way of synthesizing NHA by means of sintering, rather than by sol-gel techniques. For these reasons, the NHA was manufactured from cortical bovine bones in all our studies. Moreover, there has been much effort to improve the mechanical properties of HA by introducing foreign oxides or finding out other alternative processes such as grain growth control. Indeed, encouraging lower AGS instead of exaggerated grain growth may be jugged useful for many applications. Since the works carried out on the correlation between AGS and physico-chemical properties of NHA were very limited, the present study was mainly focused on its grain growth. A carful combination between the main parameters controlling NHA production such as milling techniques, compacting pressure, sintering temperature and holding time may lead to an interesting NHA based bio-ceramics. In this way, a simple and energetically vibratory multidirectional milling system using bimodal distribution of highly resistant ceramics has been used for obtaining sub-micron sized NHA powders. For example, the AGS was ranged between 0.75 and $1.40 \mu \mathrm{m}$ (using intercept method) when NHA samples were sintered at $1250{ }^{\circ} \mathrm{C}$ for 15 and 480 min, respectively.
\end{abstract}

DOI: 10.12693/APhysPolA.127.1161

PACS: $81.05 . J e, 81.20 . \mathrm{Ev}$

\section{Introduction}

Hydroxyapatite $\left[\mathrm{Ca}_{10}\left(\mathrm{PO}_{4}\right)_{6}(\mathrm{OH})_{2}\right]$ is well known as the mineral component of bones and teeth. Thus, it is one of the most attractive materials for human hard tissue implants [1-4].The biocompatibility of this ceramic is good enough that, when used as an implant material, it forms a direct bonding with the neighboring bone [5]. There are generally two main types of HA: natural and synthetic HA [6]. Nevertheless, the mechanical properties of HA are poor, especially in wet environment [7]. Hence, there has been much effort to improve the mechanical properties of HA by introducing foreign oxides or controlling its microstructure, in order to avoid exaggerating grain growth which may bring down their mechanical strength [5-7]. A carful combination between the main parameters controlling NHA production such as milling techniques, compacting pressure, sintering temperature and holding time may lead to an interesting NHA based bio-ceramics. In this way, a simple and energetically vibratory multidirectional milling system, using bimodal distribution of highly resistant ceramics, has been used for obtaining sub-micron sized NHA powders [8]. Fortunately, Algeria is one of the countries in the world that have abundantly available raw materials. Mainly: calcite $\left(\mathrm{CaCO}_{3}\right)$, dolomite $\left(\mathrm{CaCO}_{3} \cdot \mathrm{MgCO}_{3}\right)$, bones (natural derived hydroxyapatite: $\mathrm{HA}$ : $\left.\mathrm{Ca}_{10}\left(\mathrm{PO}_{4}\right)_{6}(\mathrm{OH})_{2}\right)$, kaolin, feldspar and quartz. Many works have already been published for valorizing these native raw materials. These topics concern advanced ceramics [9-15], ceramic mem-

${ }^{*}$ corresponding author; e-mail: eharabi84@gmail.com branes [16-22] and bioceramics [23-29]. Consequently, an attempt has been dictated in order to use abundantly available NHA as a local raw material for NHA based ceramics elaboration.

\section{Experimantal procedures}

\subsection{Preparation of specimens}

The starting material, used in this work, was NHA obtained by calcination of cortical bovine bone at $800^{\circ} \mathrm{C}$ for $4 \mathrm{~h}$ to remove the organic matter. After that, the calcined bone was dry milled for $30 \mathrm{~min}$. The pure NHA powder was wet milled for $2 \mathrm{~h}$, using a homemade particular vibratory milling setup [8]. Afterwards, it was dried and compacted at $75 \mathrm{MPa}$ under cold pressing. Subsequently, the compacted samples were sintered at $1250^{\circ} \mathrm{C}$ for different time periods.

\subsection{Characterizations}

Phase compositions of prepared samples were identified by X-ray diffraction (XRD) (BRUKER, D8 ADVANCE) (Karlsruhe, Germany) with a $\mathrm{CuK}_{\alpha}$ radiation $(\lambda=0.154 \mathrm{~nm})$ and a Ni filter, working voltage $40 \mathrm{kV}$, and working current $30 \mathrm{~mA}$. The microstructure of the sintered samples were observed using a SEM (HITACHI, JSM-6301 F) (Tokyo, Japan) working at a $15 \mathrm{kV}$ as an accelerating voltage. Before SEM observation, all samples were gold coated. The bulk density was determined using Archimedes method.

\section{Results and discussion}

Figure 1 shows a typical spectrum of NHA powders obtained by using a simple and energetically vibratory multidirectional milling system. Due to the vibration 
and rotation the dispersion increases; which causes powerful collisions; subsequently the particle size decreases. The XRD shows that the initial calcined powder is hydroxyapatite (HA) with the following chemical composition $\mathrm{Ca}_{10}\left(\mathrm{PO}_{4}\right)_{6}(\mathrm{OH})_{2}$. In addition, this spectrum shows also that all these peaks belong only to HA structure.

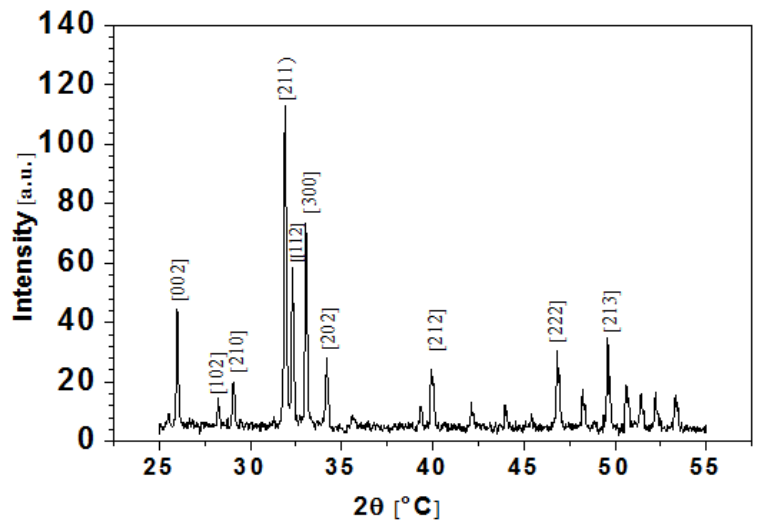

Fig. 1. XRD spectrum of NHA powder, calcined at $800{ }^{\circ} \mathrm{C}$ for $4 \mathrm{~h}$.

The sintering time is an important parameter which may influence significantly the microstructure. The prepared samples were sintered at $1250^{\circ} \mathrm{C}$ for different times ranged between 30 and $720 \mathrm{~min}$, whereas the densities of these samples were calculated from the measured volume and the weight. The obtained results illustrated in Fig. 2 show that there are three different stages. A state of constant relative density is reached for samples sintered during period of 30 and $60 \mathrm{~min}$, because this time is not enough to eliminate a high amount of pores. However, in the range between 60 and $120 \mathrm{~min}$, the relative density increased with a ratio of $5 \%$ and this is may be due to the decrease in the pore ratio. Afterwards, in the range between 120 and 720 min there is a low increase in relative density of about $1 \%$ and this is due to the grain growth. In this study, the relative density of samples sintered at $1250{ }^{\circ} \mathrm{C}$ for 30 and 720 min were $85.8 \pm 0.6$ and $93.9 \pm 0.6 \%$, respectively. These values are, indeed, significantly important when compared with those reported in the literature [30].

Figure 3 illustrates representative microstructure of samples sintered for different times which confirmed the relative density variation. Figure $3 \mathrm{a}$ illustrates the microstructure of $\mathrm{NHA}$ sintered at $1250^{\circ} \mathrm{C}$ for $15 \mathrm{~min}$, where a large amount of pores can be observed, which explains the low relative density. Also, the samples sintered at the same temperature for 30 min behave similarly as given in Fig. 3b. By contrast, in Fig. 3c, 3d, 3e and 3f, the samples are well sintered. Furthermore, Fig. 3c and $3 \mathrm{~d}$ shows a significant improvement in the grain growth, especially for longer sintering time and a better sintering. The microstructure of NHA shows a bi-modal distribution of grains which means that there are small and larger grains, the first one improves the mechanical properties

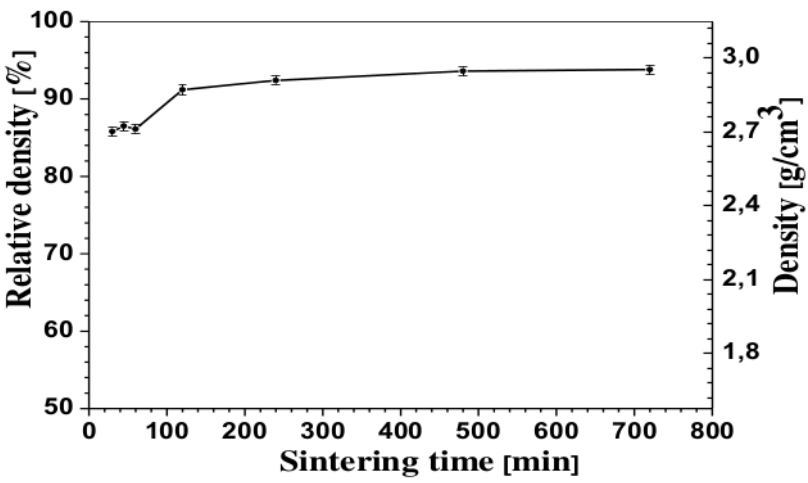

Fig. 2. Variation of the relative density as a function of the sintering time.

whereas the second one may ameliorate the wearing resistance of products [31].
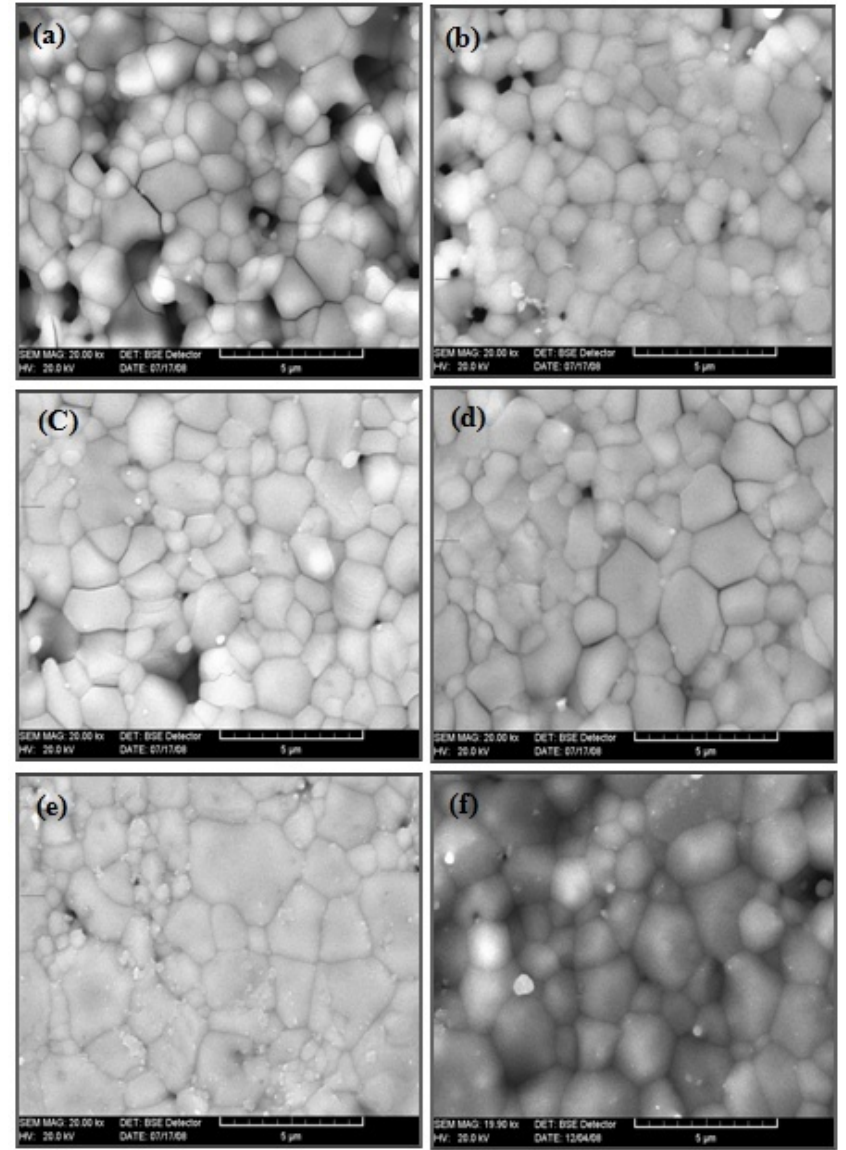

Fig. 3. SEM images of NHA sintered at $1250{ }^{\circ} \mathrm{C}$ for different time periods of: a $(15 \mathrm{~min}) ; \mathrm{b}(30 \mathrm{~min}) ; \mathrm{c}$ (45 $\min ) ; \mathrm{d}(60 \mathrm{~min}) ; \mathrm{e}(240 \mathrm{~min}) ; \mathrm{f}(480 \mathrm{~min})$.

Figure 4 shows the variation of grain size with the variation of sintering time, where the grain size is calculated by intercept method [32]. It can be noticed that there are three different stages which confirm the previous results. 


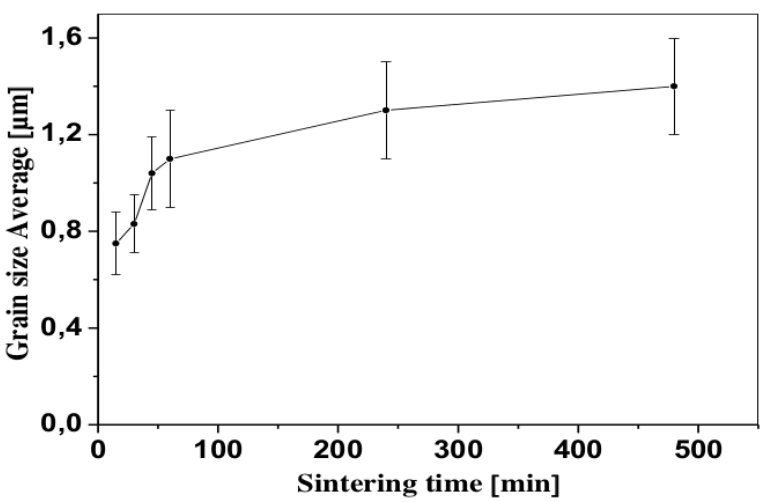

Fig. 4. Variation of grain size as a function of sintering time for samples sintered at $1250{ }^{\circ} \mathrm{C}$.

In this study, the sintering temperature of $1250{ }^{\circ} \mathrm{C}$ has been chosen because the grain growth is important and quite slow. Contrary, at high temperatures the grain growth is sharply fast, that is why it cannot be observed. However, at low temperatures, the grain growth is slower and needs a longer sintering time.

\section{Conclusions}

In order to improve densification and grain growth, NHA samples were sintered for different times at $1250^{\circ} \mathrm{C}$. The relative density was ranged between 86 and $94 \%$. This value is slightly higher than those of NHA prepared using other usual techniques even with additions such as mullite. As far as intercept method is concerned, grain size was ranged between 0.75 and $1.40 \mu \mathrm{m}$.

\section{References}

[1] L.L. Hench, J. Am. Ceram. Soc. 74, 1487 (1991).

[2] F.Z. Mezahi, H. Oudadesse, A. Harabi, A. LucasGirot, Y. Le Gal, H. Chaair, G. Cathelineau, J. Therm. Anal. Calorim. 95, 21 (2009).

[3] A. Harabi, D. Belamri, N. Karboua, F.Z. Mezahi, J. Therm. Anal. Calorim. 104, 383 (2011).

[4] L.L. Hench, J. Wilson, Advanced series in ceramics: An introduction of bioceramics, In: Hench L.L., Wilson J., editors. World Scientific Publishing: Singapore, Vol 1. p. 1-24 1993.

[5] J. Huaxia, P.M. Marquis, J. Mater. Sci. 28, 1941 (1993).

[6] Y.M. Kong, S. Kim, H.E. Kim, I.S. Lee, J. Am. Ceram. Soc. 82, 2963 (1999).

[7] R. Rao Ramachandra, T.S. Kannan, Mater. Sci. Eng. C 20, 187 (2002).

[8] A. Harabi, A simple and energetically vibratory multidirectional milling system using bimodal distribution of highly resistant ceramics: Applied on hydroxyapatite derived from natural cortical bones, Algerian Patent June 24 $4^{\text {th }}, 1303932013$.
[9] A. Harabi, S. Achour, J. Mater. Sci. Lett. 18, 955 (1999).

[10] M.R. Boudchicha, S. Achour, A. Harabi, J. Mater. Sci. Lett. 20, 215 (2001).

[11] A. Mecif, J. Soro, A. Harabi, J.P. Bonnet, J. Am. Ceram. Soc. 93, 1306 (2010).

[12] S. Achour, A. Harabi, N. Tabet, Mater. Sci. Eng. B 42, 289 (1996).

[13] A. Toumiat, S. Achour, A. Harabi, N. Tabet, M. Boumaour, M. Maallemi, Nanotechnology 17, 658 (2006).

[14] O. Bourbia, S. Achour, N. Tabet, M. Parlinska, A. Harabi, Thin Solid Films 515, 6758 (2007).

[15] A. Guechi, S. Ahour, A. Harabi, Key Eng. Mater. 264-268, 257 (2004).

[16] F. Bouzerara, A. Harabi, S. Achour, A. Larbot, J. Eur. Cer. Soc. 26, 1663 (2006).

[17] A. Harabi, F. Bouzerara, S. Condom, Des. Wat. Treat. 6, 222 (2009).

[18] B. Boudaira, A. Harabi, F. Bouzerara, S. Condom, Des. Wat. Treat. 9, 142 (2009).

[19] F. Bouzerara, A. Harabi, S. Condom, Des. Wat. Treat. 12, 415 (2009).

[20] A. Harabi, A. Guechi, S. Condom, Procedia Engineering 33, 220 (2012).

[21] F. Bouzerara, A. Harabi, B. Ghouil, N. Medjemem, B. Boudaira, S. Condom, Procedia Engineering 33, 278 (2012).

[22] A. Harabi, F. Zenikheri, B. Boudaira, F. Bouzerara, A. Guechi, L. Foughali, J. Eur. Ceram. Soc. 34, 1329 (2014).

[23] F.Z. Mezahi, H. Oudadesse, A. Harabi, A. LucasGirot, Y. Le Gal, H. Chaair, G. Cathelineau, J. Therm. Anal. Calorim. 95, 21 (2009).

[24] F.Z. Mezahi, H. Oudadesse, A. Harabi, Y.L. Gal, Int J. Appl. Ceram. Technol. 9, 529 (2012).

[25] A. Harabi, S. Chehlatt, J. Therm. Anal. Calorim. 111, 203 (2013).

[26] A. Harabi, S. Zouai, Int. J. Appl. Ceram. Technol. 11, 31 (2014).

[27] A. Lucas-Girot, F.Z. Mezahi, M. Mami, H. Oudadesse, A. Harabi, M. Le Floch, J. Non-Cryst. Solids 357, 3322 (2011).

[28] F.Z. Mezahi, A. Lucas-Girot, H. Oudadesse, A. Harabi, J. Non-Cryst. Solids 361, 111 (2013).

[29] F.Z. Mezahi, A. Harabi, S. Zouai, S. Achour, D. Bernache-Assollant, Mater. Sci. Forum. 492 493, 241 (2005).

[30] S.J. Kalita, S. Bose, H.L. Hosick, A. Bandyopadhyay, Biomaterials 25, 2331 (2004).

[31] S. Nath, A. Day, A.K. Mukhopadhyay, B. Basu, Mater. Sci. Eng. A 513-514, 197 (2009).

[32] A. Harabi, Ph.D. Thesis, Manchester Materials Science Centre, UMIST, Manchester, UK 1990. 